\title{
Lendo Graciliano Ramos nos Estados Unidos ${ }^{1}$
}

\author{
Darlene J. Sadlier ${ }^{2}$
}

\section{Resumo}

Os estudos sobre a obra de Graciliano Ramos têm abordado numerosos aspectos, e não há dúvida de que seus livros despertam interesse permanente entre os críticos norte-americanos. Contudo, apesar do volume substancial de ensaios acadêmicos sobre a obra do autor alagoano, não existe um estudo centrado na história de sua recepção crítica nos Estados Unidos - assunto de que trata o presente ensaio. Tal discussão revela momentos históricos definidores, bem como tendências ideológicas e formações culturais que têm influenciado a maneira pela qual a crítica daquele país seleciona, lê e escreve sobre a literatura de outras regiões.

\section{Palavras-chave}

Graciliano Ramos, crítica norte-americana, Estados Unidos, tradução, romance brasileiro, literatura comparada.

Recebido em 5 de agosto de 2011

Aprovado em 8 de dezembro de 2011

1 Tradução revista por Dra. Leila Gouvêa.

2 Professora na Indiana University, Bloomington, EUA. E-mail: sadlier@indiana.edu 


\title{
Reading Graciliano Ramos in the United States
}

\author{
Darlene J. Sadlier
}

\section{Abstract}

Studies of the work of Graciliano Ramos have approached numerous aspects of his oeuvre, and there can be no doubt that his books have stirred a lasting interest among North-American critics. However, despite the substantial volume of academic essays on this Alagoan author, no study covers the history of his critical reception in The United States - a situation the present article hopes to redress. A discussion of this topic raises defining historical moments, as well as ideological persuasions and cultural backgrounds that have influenced the way US critics select, read and write about literature from other regions.

(4) Keywords

Graciliano Ramos, North-American criticism, The United States, translation, the Brazilian novel, comparative literature. 


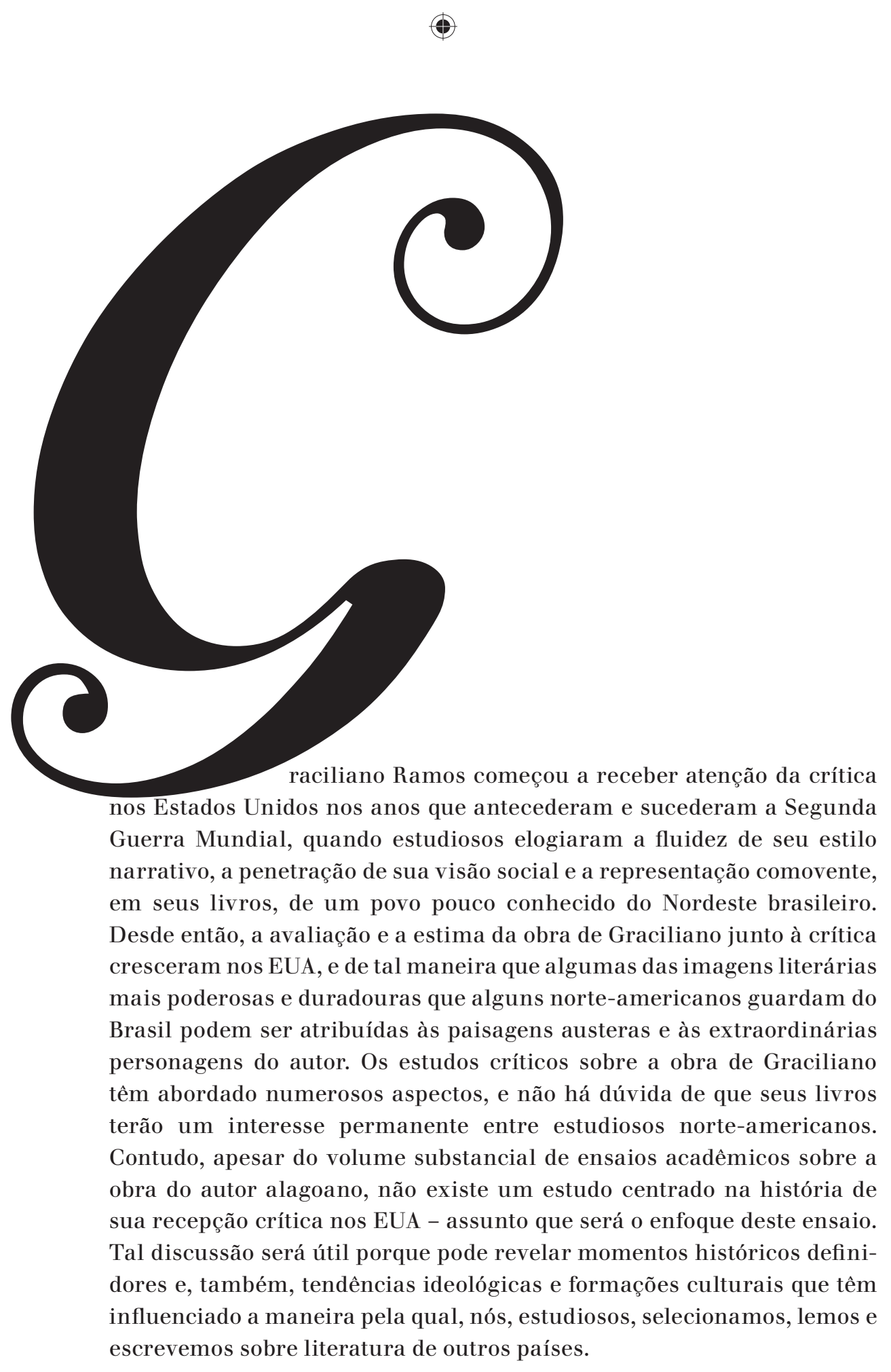

nos Estados Unidos nos anos que antecederam e sucederam a Segunda Guerra Mundial, quando estudiosos elogiaram a fluidez de seu estilo narrativo, a penetração de sua visão social e a representação comovente, em seus livros, de um povo pouco conhecido do Nordeste brasileiro. Desde então, a avaliação e a estima da obra de Graciliano junto à crítica cresceram nos EUA, e de tal maneira que algumas das imagens literárias mais poderosas e duradouras que alguns norte-americanos guardam do Brasil podem ser atribuídas às paisagens austeras e às extraordinárias personagens do autor. Os estudos críticos sobre a obra de Graciliano têm abordado numerosos aspectos, e não há dúvida de que seus livros terão um interesse permanente entre estudiosos norte-americanos. Contudo, apesar do volume substancial de ensaios acadêmicos sobre a obra do autor alagoano, não existe um estudo centrado na história de sua recepção crítica nos EUA - assunto que será o enfoque deste ensaio. Tal discussão será útil porque pode revelar momentos históricos definidores e, também, tendências ideológicas e formações culturais que têm escrevemos sobre literatura de outros países.

revista ieb $n 542012$ set./mar. p. 3I-52 


\section{Graciliano e as relações culturais nos anos da "boa vizinhança"}

Embora notícias bibliográficas sobre as obras de Graciliano aparecessem nas revistas acadêmicas Books Abroad e Handbook of Latin American Studies desde os meados e fins da década de 1930, foi apenas em 1940, quando o ensaio de Samuel Putnam intitulado "The Brazilian social novel (1935-1940)" apareceu em The Inter-American Quarterly ${ }^{3}$, que sua reputação literária nos EUA começou a emergir. Estudioso de literatura e admirador de Machado de Assis e Euclides da Cunha, Putnam escrevia também para The Daily Worker, órgão oficial do Partido Comunista dos EUA - entidade legal no país. De fato, parte expressiva da cultura intelectual norte-americana dos anos de 1930 era de tendência radical ou esquerdista, de uma ou outra forma. Em seu ensaio sobre o romance social, Putnam reserva à obra de Graciliano a sua apreciação mais alta:

É do campo considerável da escrita regionalista que emerge um talento impressionante na pessoa de Graciliano Ramos, cuja reputação foi estabelecida definitivamente com Angústia de 1936 (seu livro São Bernardo apareceu dois anos antes). Angústia é notável pelo uso que faz do monólogo interior, à la Joyce, aplicado a um tema social; mas é com seu livro Vidas secas, de 1938, que Ramos começa a revelar plenamente essas potencialidades, que já deram oportunidade a comparações entre ele e Gogol, Gorki e outros realistas russos... Ele escreve sobre a alma humana submetida à servidão; suas paisagens, como suas personagens, são secas; e seu método é como aquele do vivisseccionista social-literário. Como Lins do Rego, o lugar ficcional de seus livros é seu Nordeste nativo, mas as telas de Graciliano são muito menores, mais concentradas, e isso lhes dá maior intensidade e efetividade. Os críticos cariocas dizem que Vidas secas não atinge a qualidade de Angústia, mas, na minha opinião (...), é um marco miliário no progresso de um escritor de quem há muito a esperar nos anos futuros. ${ }^{4}$

The Inter-American Quarterly foi uma das primeiras revistas especificamente dedicadas à literatura, história e artes das três Américas, e o ensaio de Putnam apareceu quase no mesmo momento

3 PUTNAM, Samuel. The Brazilian social novel (1935-1940). The Inter-American Quarterly, p. 5-12, 1940.

4. Idem, ibidem, p. 11-12. 
em que o presidente Franklin D. Roosevelt criou o Office of the Coordinator of Inter-American Affairs (CIAA), agência cujo objetivo principal era fortalecer as relações culturais entre os EUA e a América Latina antes e durante a Segunda Guerra Mundial. Os EUA se interessavam pelo Brasil, sobretudo em razão de seu tamanho geográfico, recursos naturais e posição estratégica no Atlântico. Por esse motivo, o CIAA investiu em intercâmbios culturais entre os dois países, financiando publicações como The Inter-American Quarterly e encorajando traduções em inglês de autores brasileiros.

É importante observar que o crítico Putnam não era propriamente um defensor desse programa governamental. Note-se, por exemplo, que ele não menciona nenhum escritor norte-americano com relação a Graciliano, passando rapidamente às suas afinidades com o modernismo europeu, sobretudo com Joyce e os que cultivaram o monologue intérieur, para enfatizar o quanto o romance Vidas secas pode ser lido em termos do realismo socialista soviético. A comparação que Putnam formula entre Graciliano e Gogol é reveladora da tendência de dar mais valor à obra de um autor russo de meados do século XIX - mesmo tratando-se de um russo quase desprovido de verdadeira experiência da vida provinciana, a qual imaginava tão brilhantemente - do que à obra de uma figura vanguardista como Joyce, fruto mais direto da observação e, sem dúvida, mais "real". As posições políticas de Putnam, que traduziu Os sertões e Casa grande e senzala para o inglês, não preocupavam os funcionários do período denominado New Deal por Roosevelt. Ele se tornou um embaixador de "boa vizinhança" no Brasil e um entusiasta de Graciliano - a tal ponto que, quando o editor nova-iorquino Alfred A. Knopf lhe pediu sugestões de títulos latino-americanos para incluir em sua notável "Série Borzoi", de traduções, Angústia foi a única recomendação de Putnam ${ }^{5}$. Dois anos depois da edição de seu ensaio de 1940, Putnam publicou um longo e provocativo artigo intitulado "Brazilian Culture under Vargas", na revista esquerdista Science and Society ${ }^{6}$. Reiterava, aí, sua admiração pela extraordinária agudeza literária de Graciliano e conjeturava que o emprego do "fluxo de consciência" e do dialeto regional em sua escrita servia principalmente para confundir os censores do DIP, e mascarar uma implícita crítica social. Putnam revelava-se cético quanto à imagem de ditador benévolo que se fazia de

5 Traduzido como Anguish por L. C. Kaplan, o romance recebeu excelentes resenhas depois do lançamento em 1946. (Cf. RAMOS, Graciliano. Anguish. Trad. L. C. Kaplan. New York: Alfred A. Knopf, 1946).

6 PUTNAM, Samuel. Brazilian culture under Vargas. Science and Society, p. 34-56, 1942. 
Vargas nos EUA, e argumentava que o encarceramento de Graciliano pelo DIP, em 1935, o tornara mais cauteloso e indireto, inclinado a evitar problemas, o que levou o escritor a "mascarar" sua ficção com uma técnica modernista difícil - avaliação que, como veremos, seria mais tarde contestada por ao menos um outro crítico.

Putnam e Knopf não eram os únicos a promover Graciliano Ramos durante os anos da política de boa vizinhança. Ensinando na Universidade da Califórnia, Erico Verissimo publicou um opúsculo em inglês, intitulado Brazilian literature: An outline (1945), no qual minimizava a importância dos autores nordestinos, ao mesmo tempo em que elogiava Graciliano como "um dos mais sólidos e profundos escritores brasileiros de hoje" escritor alagoano nas mãos do DIP, que transformaram o autor na pessoa "sombria" que escreveu livros "amargos". Ao contrário de Putnam, Verissimo não se refere diretamente à prisão de Graciliano, provavelmente porque Vargas ainda estava no poder e qualquer crítica explícita ao regime poderia ter repercussões para um brasileiro que então planejava regressar a seu país. E contrapondo-se à avaliação de Putnam sobre Angústia, Verissimo não viu nada suficientemente psicológico na ficção de Graciliano para justificar uma comparação com "um Joyce, um Proust, ou um Mauriac". Em vez disso, ele comparou o escritor com Erskine Caldwell e James T. Farrell, romancistas norte-americanos que se encontravam então no mais alto de sua fama como autores esquerdistas de ficção naturalista e autores, respectivamente, de Tobacco road, que retrata a vida dos lavradores no Sul empobrecido, e da trilogia de Studs Lonigan, que descreve a comunidade de imigrantes irlandeses em uma Chicago industrializada. A evocação por Verissimo de tais figuras serviu para enfatizar o realismo áspero e local e, de certa maneira, a visão política de Graciliano Ramos.

Hoje, parece significativo que Verissimo tenha deixado de mencionar William Faulkner, na verdade um autor muito mais interessante para se comparar com o escritor brasileiro, e que viria depois a se tornar, efetivamente, um nome frequente nos estudos literários comparados de Graciliano. O renome de Faulkner ainda não estava plenamente estabelecido nos EUA quando Verissmo publicou seu livro, mas qualquer crítico disposto a valorizar o modernismo literário poderia ter notado que ambos, Faulkner e Graciliano, voltavam-se para uma sociedade

7 VERISSIMO, Erico. Brazilian literature: An outline. New York: Macmillan Company, 1945. p. 152-153.

8 Idem, ibidem, p. 152. 
quase feudal, a qual representavam mediante uma moderna e idiossincrática técnica narrativa.

\section{A Guerra Fria e os estudos de Literatura Comparada nos EUA}

É sempre arriscado generalizar, mas o fim da década de 1940 e os primeiros anos de 1950 foram marcados por ao menos dois eventos sociopolíticos que influenciaram a crítica literária do período. O primeiro foi a Guerra Fria, que começou oficialmente em 1948, com a declaração de Winston Churchill sobre uma "cortina de ferro" que descia sobre a Europa. Logo se seguiram o bloqueio britânico, o começo da guerra na Coreia, a aprovação da Lei Taft-Hartley pelo Congresso dos EUA (que baniu os sindicatos comunistas e exigiu juramento de lealdade dos funcionários governamentais) e um Red Scare (medo dos comunistas), que afetaram toda a produção cultural no país. Segundo, e quase coincidentemente, o ensino universitário se tornou muito mais acessível; durante a década de 1950, houve um apreciável crescimento da crítica acadêmica, grande parte da qual, ao contrário das duas décadas anteriores, de caráter esteticista e formalista. A "Nova Crítica" ascendia no período, e departamentos de literatura comparada, em sua maioria focados na produção da Europa Ocidental, foram criados nas instituições de maior relevo.

Nos anos imediatamente posteriores à Segunda Guerra Mundial, referências a Graciliano apareceram no Charts of Brazilian literature (1947), de Joseph Newhall Lincoln, que foi a primeira bibliografia importante da literatura brasileira publicada nos EUA. Discordando da avaliação de Erico Verissimo sobre o restante da literatura nordestina do Brasil, Lincoln comentou brevemente as "afinidades estilísticas" entre Graciliano, Proust e Joyce ${ }^{9}$. Suas observações repetem a avaliação anterior do Putnam, fundamentada em sua familiaridade com traduções de importantes autores europeus. Mas, diversamente de Putnam e também de Verissimo, Lincoln evitou qualquer comparação entre Graciliano e os realistas-sociais russos ou os realistas-esquerdistas norte-americanos. Já em fins dos anos 1940, era possível constatar uma divisão de caráter ideológico na crítica a Graciliano Ramos nos EUA, entre os que consideravam sua obra em termos do realismo social e, de outro lado, os

9 LINCOLN, Joseph Newall. Charts of Brazilian literature. Ann Arbor, Michigan: 1947. p. 66. 
que preferiam enfatizar suas ligações com o Modernismo - divisão que continua a nortear sua recepção até hoje.

A antiga esquerda não emudeceu completamente durante esse período. Em 1948, dois anos antes de seu falecimento, Putnam publicou Marvelous journey: A survey of four centuries of Brazilian writing ${ }^{10}$, até hoje uma das mais informativas histórias da literatura brasileira em inglês. Nesse livro, Putnam articula uma preocupação sobre o futuro das relações culturais interamericanas e da mudança do foco político norte--americano para a Europa. Uma das perguntas que propõe aos leitores é se Graciliano e outros autores brasileiros continuariam a ser lidos e traduzidos nos EUA. Talvez em decorrência da ansiedade suscitada por essa dúvida, em Marvelous journey Putnam faz várias referências a Graciliano e ao modernismo literário. Também chama a atenção para aquilo que denomina o "novo regionalismo", expressão que ele usa em referência aos assuntos que então atraíam os escritores nordestinos e formavam a base do livro Brazil: An interpretation (1945), de Gilberto Freyre ${ }^{11}$, comentado por Putnam. Este ensaísta reservava atenção especial às implicações revolucionárias da obra de Graciliano e às dificuldades inerentes de escrever sobre o fascismo - ideias que ele apresentou inicialmente em seu artigo "Brazilian culture under Vargas" (ver nota 5). Preocupava-se consideravelmente também com o fato de haver, naquele momento, apenas três ou quatro traduções de autores brasileiros nas livrarias. Ao mesmo tempo, evitou uma perspectiva pessimista, elogiando Angústia como uma obra original e magistral que "não poderia ter sido produzida em qualquer outro país, ou em qualquer outra época no Brasil"12.

Se Putnam foi o maior responsável por chamar a atenção da crítica para Graciliano nos EUA, Ralph Edward Dimmick formulou uma estrutura mais teórica para a contextualização da obra do escritor. $O$ estudo de Dimmick, "The Brazilian literary generation of 1930", publicado em $1951^{13}$, foi lido largamente por especialistas acadêmicos e acatado como um meio de classificar a escola "regionalista" descrita por Putnam. Quando o ensaio de Dimmick apareceu, havia um enfoque crítico em voga nos EUA que se chamava "geracional". Em sua maior parte, os

10 PUTNAM, Samuel. Marvelous journey: A survey of four centuries of Brazilian writing. New York: Alfred A. Knopf, 1948.

11 FREYRE, Gilberto. Brazil: An interpretation. New York: Alfred A. Knopf, 1945.

12 PUTNAM, Samuel. Marvelous journey: a survey of four centuries of Brazilian writing. op. cit. p. 216.

13 DIMMICK, Ralph Edward. The Brazilian literary generation of 1930. Hispania 43, 2. p. 181-187, maio 1951. 
métodos deste enfoque foram importados da Alemanha, onde se havia adotado uma forma algo seca e enciclopédica. Dimmick se inspirou no ensaio seminal "Die literarischen Generationen", do teórico alemão Julius Petersen ${ }^{14}$, e pôs em relevo seis requisitos para a classificação geracional: proximidade de idade, semelhança de educação, contato pessoal entre os indivíduos, exposição mútua a um evento histórico (no caso brasileiro, a Revolução de Outubro de 1930), um impacto tangível na consciência nacional e uma linguagem comum.

A metodologia de Petersen foi questionada mais tarde, entre outros, por Raymond Williams ${ }^{15}$, cujo conceito de frações culturais remete a uma sociologia com maior nuance e a um modo mais complexo de compreender a formação de classe social. Sem embargo, Dimmick nos chama a atenção para um número significativo de escritores brasileiros talentosos, incluindo Graciliano e Amando Fontes, que começaram a publicar nos anos 1930 e compartilhavam certas características. Embora a ênfase de Dimmick recaísse no aspecto geracional, e não nos indivíduos, ele destacou Graciliano, observando que, apesar de ter recebido menor quantidade de educação formal, foi o mais admirado pelos críticos no Brasil ${ }^{16}$. O ensaio de Dimmick serviu também, e talvez inconscientemente, a um propósito relevante na maioria dos escritos sobre as gerações ou escolas: conferiu capital cultural a certos escritores menores, ao mesmo tempo em que elevou a reputação de Graciliano como o escritor mais significativo de um importante movimento.

A ênfase de Dimmick no romance de protesto social brasileiro abriu caminho para o estudo seminal de Fred P. Ellison, Brazil's new novel: Four Northeastern masters (1954) ${ }^{17}$, que contém capítulos sobre Graciliano, Rachel de Queiroz, Jorge Amado e José Lins do Rego. Publicado pela editora da Universidade da Califórnia, o livro suscitou entusiasmo nas academias em relação a este grupo de escritores, a quem foi dado um tipo de rótulo ou marca comercial. Segundo Ellison, os romances desses autores eram regionalmente focados, socialmente comprometidos, formalmente cativantes e singularmente influentes na vida intelectual brasileira. Porém, em sua análise de Graciliano e de outros, ele rejeita claramente o termo "regional", utilizado com frequência para descrever

14. PETERSEN, Julius. Die litearischen Generationen. Berlin: Junker und Dünnhaupt, 1930.

15 WILLIAMS, Raymond. Culture. Great Britain: Fontana, 1981.

16 DIMMICK, Ralph Edward. op. cit. p. 182.

17 ELLISON, Fred P. Brazil's new novel: Four Northeastern masters. Los Angeles: University of California Press, 1954 . 
a nova ficção nordestina, preferindo a classificação mais atraente e modernista de "novo".

A leitura sensível e cronológica de Graciliano por Ellison, que examina cada um de seus livros, desde Caetés até Infância, abre uma janela para a análise do desenvolvimento do escritor, e constitui um depoimento de sua posição a respeito de assuntos como a luta de classes sociais, a injustiça social e a pobreza. Ellison se estende sobre os protagonistas masculinos nos romances, cujas inseguranças pessoais e obsessões, além das experiências com a pobreza, os conduzem à cólera, ao assassinato e à loucura. Inadvertido da reação da Nova Crítica contra a análise biográfica, ou simplesmente desconsiderando-a, Ellison aprofunda a análise das semelhanças entre as experiências do menino Graciliano e as de seu protagonista ficcional, Luís da Silva, em Angústia. Chega até a descrever Angústia como um roman à clef, e enfatiza ao longo de todo o seu estudo a natureza autobiográfica da pobreza, das iniquidades sociais e do desespero pessoal, que aparecem em outros romances. Ao mesmo tempo, tenta dissociar Graciliano de qualquer tendência política em particular. Apesar das óbvias posições esquerdistas do escritor alagoano, Ellison comenta que "nada em [sua] obra serviria diretamente como propaganda política"18. Esse foi um argumento típico da época da Guerra Fria, e seria repetido e mesmo rejeitado por outros críticos nos anos posteriores.

Brazil's new novel é o primeiro estudo em inglês a destacar a recepção de Graciliano no Brasil, além de alguns aspectos filosóficos e formais já observados pelos críticos brasileiros, os quais trouxeram o estudo de Graciliano à órbita da história literária nos EUA. O ensaio cita, entre outros, Floriano Gonçalves ${ }^{19}$, que escreveu sobre o naturalismo e determinismo de Graciliano; Osório Borba ${ }^{20}$, que focalizou sua versão estilizada da fala sertaneja; e Guilherme de Figueiredo ${ }^{21}$, que abordou seu enfoque "matemático" da linguagem. Ele diverge fortemente da avaliação de Putnam de que o monólogo interior e outros artifícios formais teriam sido a maneira de Graciliano mascarar suas preocupações sociais e políticas. Para Ellison, o estilo do autor alagoano não era um subterfúgio, senão uma estratégia artística propositada e "um método engenhoso

18 Idem, ibidem, p. 116.

19 GONÇALVES, Floriano. Graciliano Ramos e o romance: Ensaio de interpretação. In: RAMOS, Graciliano. Caetés. 2. ed. Rio de Janeiro: José Olympio, 1937.

20 BORBA, José Osório de Morais. A comédia literária. Rio de Janeiro: Alba Editora, 1946.

21 FIGUEIREDO, Guilherme de. Alguns romances de '38. Anuário brasileiro de literatura, 1939. Rio de Janeiro: Irmãos Pongetti, 1939. 
de combinar o social com o filosófico"22. Em conclusão, o estudioso nos alerta para a tendência de Graciliano Ramos de adaptar técnicas formais associadas com o conto, sobretudo em Vidas secas, em que uma narrativa unificada emerge de uma série de retratos psicológicos autônomos - incluindo o retrato da cachorra Baleia, que se tornaria uma das figuras mais conhecidas da literatura brasileira.

\section{O crescimento do interesse pelo português e Graciliano no sistema escolar dos EUA}

O conflito dos superpoderes durante a Guerra Fria foi acompanhado por um espírito de internacionalismo nos EUA. Por razões de segurança nacional, surgiu a necessidade de se manter o país informado sobre as diferentes regiões e línguas do mundo. Em 1958, após o lançamento soviético do Sputnik, o governo norte-americano fez aprovar o National Defense Education Act Title VI, a fim de apoiar o estudo de línguas estrangeiras e a formação de centros de pesquisas regionais nas universidades. O estudo do Português recebeu fundos e, pelo país inteiro, foram criados institutos para o estudo do Brasil e da América Latina. Três anos mais tarde, em 1961, o Congresso aprovou a Lei FulbrightHays, que subsidiava a pesquisa de alunos de pós-graduação no Brasil e em países do mundo inteiro. Ao final da década de 1970, Graciliano foi tema de quatro teses de doutorado ${ }^{25}$, e surgiram três novas traduções em inglês de seus livros ${ }^{24}$, além de uma bibliografia anotada, numerosos ensaios e o livro de Richard A. Mazzara, Graciliano Ramos ${ }^{25}$.

22 ELLISON, Fred P. Brazil's new novel: Four Northeastern masters. op. cit. p. 41.

23 Vejam-se as teses: COURTEAU, Joanna. The world view in the novels of Graciliano Ramos. Tese (Doutorado em Português), University of Wisconsin, 1971; GUEDES, Bernadette. A translation of Graciliano Ramos'Caetés. Tese (Doutorado em Português) University of South Carolina, 1976; OLIVEIRA, Celso Lemos de. A translation of Graciliano Ramos' Childhood. Tese (Doutorado em Literaturas Românicas), University of Michigan, 1977; HARMON, Ronald Max. The conveyance of ideology through style in the novels of Graciliano Ramos. Tese (Doutorado em Português), University of California, 1978.

24. RAMOS, Graciliano. Barren Lives. Trad. Ralph Edward Dimmick. Austin: University of Texas Press, 1965; Childhood. Trad. Celso de Oliveira. London: Peter Owen, 1979; São Bernardo. Trad. R. L. Scott-Buccleuch. New York: Taplinger Publishing Co., 1979.

25 Cf. CUNHA, Antonio C. R. Graciliano Ramos: an annotated bibliography. San Diego State College, 1970; HARMON, Ronald M. Symbolism in Graciliano Ramos' Angústia. Proceedings: Pacific-Northwest Council on Foreign Languages 29, 1, p. 10o-103, 1978; MAZARRA, Richard A. Graciliano Ramos. New York: Twayne Publishers, Inc., 1974. 
Nos anos 1960 e 1970, os EUA também viveram um intenso período de turbulência política. Foi o período do movimento pelos direitos civis, dos assassinatos de John F. Kennedy, Robert Kennedy e Martin Luther King; dos protestos estudantis contra a guerra do Vietnã; e do escândalo de Watergate e do impeachment de Richard Nixon. A maioria dos acadêmicos nos EUA era de tendência liberal-esquerdista e, em conformidade com o clima político, vários estudos sobre Graciliano se dedicaram aos temas da injustiça social, da inquietação política e da luta pelos valores democráticos. Entre eles, incluem-se os ensaios de Maria Isabel Abreu ("O protesto social na obra de Graciliano Ramos") ${ }^{26}$ e de Russell Hamilton ("Character and idea in Graciliano Ramos") ${ }^{27}$. Outras publicações, como o ensaio "Pessimism in Graciliano Ramos", de Marie Sovereign" ${ }^{28}$, focalizaram o tom sombrio, o determinismo social e a representação do sofrimento humano. Em decorrência da ascensão dos estudos sobre teoria e crítica marxista na Academia, a comparação feita por Putnam, em 1940, entre Graciliano e os escritores russos ganhou nova importância, embora este ensaísta nem sempre recebesse crédito pela comparação. Por exemplo, no prólogo de sua tradução de Vidas secas (1965), Ralph Dimmick comenta que Graciliano leu não só Zola, Eça e Balzac, mas também traduções em português de Gorki e Dostoievski ${ }^{29}$.

Durante a década de 1960, ao menos dois ensaios propuseram que Graciliano fosse lido como um escritor social-realista, e que o romance Vidas secas seria, em última análise (embora talvez só implicitamente), otimista a respeito da resistência e da sobrevivência humanas ${ }^{30}$. Em meados da década de 1970, seus romances constituíram leituras obrigatórias para os estudantes nos programas de Português, e os artigos sobre os romances focalizaram quase exclusivamente sua contundente crítica social. Mas esse tipo compromissado de leituras, que se tornaram comuns, foi refutado por Jon S. Vincent, num artigo intitu-

26 ABREU, Maria Isabel. O protesto social na obra de Graciliano Ramos. Hispania 48, 4. p. 850-855, dez. 1965 .

27 HAMILTON, Russell. Character and idea in Ramos' Vidas secas. Luso-Brazilian Review 5 , 1, verão 1968. p. 86-92.

28 SOVEREIGN, Marie L. Pessimism in Graciliano Ramos. Luso-Brazilian Review 7,1 p. 57-63, verão 1970 .

29 Cf. Introduction by Ralph Edward Dimmick. In: RAMOS, Graciliano. Barren Lives. op. cit. p. xi.

zo Vejam-se, por exemplo, MAZZARA, Richard A. New perspectives on Graciliano Ramos. Luso-Brazilian Review 5, 1, p. 93-100, verão 1968; e HAMILTON, Russell Character and idea in Graciliano Ramos'Vidas secas. Luso-Brazilian Review 5, 1, verão 1968. p. 86-92. 
lado "Dialectics of defeat" (1976) ${ }^{31}$. Ele começa expressando dúvida (à la Raymond Williams) em relação à uniformidade daquilo que Dimmick chamou a "Geração de 1930", e à noção largamente aceita de que os romances nordestinos consistiam, antes de mais nada, em denúncia de uma classe social hegemônica e em uma chamada para a revolução. Vincent escreve:

(...) Creio que a interpretação dos quatro romances de Ramos como tratados políticos sobre o colapso da sociedade burguesa é uma injustiça, uma deformação artificial e redutora da verdadeira singularidade estética dos romances em questão, algo como querer provar que a trilogia de Tolkien seja uma alegoria da Segunda Guerra Mundial - tudo muito interessante, mas não muito produtivo, nem especialmente ilustrativo. Se há um certo encanto pitoresco nesse tipo de exercício, há também uma inerente e desafortunada inclinação que relega a experiência do romance a uma posição terciária, nele centrando-se apenas como um depoimento ou persuasão. ${ }^{32}$

O título do ensaio de Vincent, "A dialética da derrota", se refere à inércia entorpecida e ao desespero das personagens que não têm saída, nas quais cada pensamento é seguido por um pensamento negativo contraditório e cada ação esperançosa é logo bloqueada. Embora divirja das interpretações sociopolíticas prevalecentes, Vincent também evoca as observações gerais desse autor sobre a intensidade psicológica das pequenas telas humanas de Graciliano e seu enfoque modernista do mundo interior do sertão, onde as personagens "secas" lutam contra uma servidão humana insuperável, em certa medida, interna. Vincent argumenta que a predominância da psicologia sobre o enredo e o tempo cronológico ou empírico em Vidas secas são prova de um tipo diferente de romance, que mais se assemelha aos experimentos modernistas inspirados pela filosofia de Henri Bergson. Para Vincent, o discurso indireto livre de Graciliano resulta em personagens altamente individualizadas, completamente diferentes dos estereótipos heroicos ou tipos coletivos que se encontram no romance radical dos anos 1930. Embora concorde que personagens como Fabiano e Sinha Vitória são vítimas da sociedade, ele

31 VINCENT, Jon S. The dialectics of defeat. In: MARTINS, Heitor (ed.). The Brazilian novel. Luso-Brazilian Literary Series, vol. 1. Bloomington: Department of Spanish and Portuguese, 1976. p. 43-58.

32 Idem, ibidem, p. 44.

43

revista ieb $\quad 454 \quad 2012$ set./mar. p. 3I-52 
rejeita a noção de que suas lutas têm ativas implicações políticas: "Ao contrário das personagens convencionais, eles não têm sucesso nem planejam um futuro, [ou] a salvação através de um sistema alternativo de valores. Por isso, a organização social ideal é construída não como um imperativo, mas como uma impossibilidade" ${ }^{3 \pi}$. Obviamente, essa avaliação vai contra a corrente das leituras utópico-esquerdistas de Putnam e outros críticos do livro. Vincent conclui que a estrutura circular de Vidas secas faz deste romance o menos otimista de Graciliano. "[A] ideia de 'se realizar", ele escreve, "é negada pela inevitabilidade de se repetir... e Ramos não oferece nenhuma indicação de que haja qualquer possibilidade de fugir desse ciclo inexorável" ${ }^{34}$.

A Nova Crítica, na prática ainda uma escola residual nos EUA, ganhou certo apoio indireto na década de 1970. No ensaio de 1972, "The language of Vidas secas" ${ }^{\prime 5}$, Dorothy M. Atkinson enfatizou a economia linguística do romance, em vez de sua política, e focalizou o emprego repetido em Graciliano de certas frases e palavras-chave. Em conjunção com o discurso indireto livre, ela demonstra que o aspecto textual "seco" da obra cria uma ideia de isolamento das personagens, incluindo suas lutas com palavras e sua pobreza cultural. Atkinson nota que entre as palavras mais repetidas no texto estão os substantivos que se referem ao corpo, como "cabeça" e "olho", e os verbos "ver" e "olhar". Se essa frequente repetição de "ver" no romance sugere alguma coisa, ela argumenta, é talvez uma ênfase no aspecto exterior ou físico das personagens e suas ações, cujas complexidades psicológicas resultam em problemas para os retirantes. Em seu ensaio, Atkinson faz ainda uma leitura semiótica e teatral, que se concentra na representação ou performance das referências textuais à comunicação não verbal:

Um sacudir da cabeça, o fechar dos olhos, um movimento da mão podem ter tanto significado como o gesto correspondente de um ator no palco ao propor a definição da personagem, e nos ajudar a entrar em seus pensamentos e sentimentos. O leitor atento notará que a cabeça pode ser sacudida de várias diferentes maneiras. Pode-se visualizar as diferenças minuciosas entre "agitar a cabeça", "balançar a cabeça", sacudir a cabeça?36

33 Idem, ibidem, p. 48 .

34. Idem, ibidem, p. 53.

35 ATKINSON, Dorothy M. The language of Vidas secas. In:__ _ CLARKE, Anthony H. (eds.). Hispanic studies in honour of Joseph Manson. Oxford: Dolphin Book Co., 1972. p. 9-20.

36 Idem, ibidem, p. 11.

44

revista ieb $n_{54} 2012$ set./mar. p. 3I-52 
Talvez a revelação mais interessante no estudo de Atkinson seja a de que, das trinta e nove ocorrências da palavra "dizer" no romance, apenas uma é usada para introduzir a fala direta. Em todos os outros casos usa-se a palavra em frases como "para bem dizer", que se refere àquilo que uma personagem pensa que diria, mas é incapaz de articular.

A volta da crítica literária na direção oposta ao ativismo social pode ser vista no livro Graciliano Ramos (1974), de Richard Mazzara. Aqui, certos atributos ou aspectos hipotéticos da obra de Graciliano são separados em categorias distintas, incluindo títulos de capítulos como "O sociólogo-psicólogo", "O psicólogo-estilista" e "O artista-filósofo" ${ }^{37}$. A contribuição mais original do estudo é a discussão de Insônia (1947) e certas semelhanças entre suas narrativas curtas e os romances do autor: os registros, o recurso ao monólogo interior, as atmosferas inquietantes e retratos de personagens incapacitadas ou empobrecidas. Mazzara argumenta que os protagonistas de Graciliano funcionam à ordem de um "Todomundo". Seu enfoque, que se mostra implicitamente conservador, considera Graciliano como um escritor preocupado com valores humanos universais, e não com um conflito social determinado.

\section{Vidas secas}

Fredric Jameson observou que um dos sintomas da cultura pós-moderna é a emergência de "Teoria" na Academia - um fenômeno que se tornou evidente nos departamentos de literatura dos EUA em fins da década de 1970 e nos anos de 1980, paradoxalmente num momento em que toda a política nacional se virava para a direita. Durante esse período, o amplo interesse pela teoria literária europeia, e sobretudo pela teoria da tradução literária, deu mais visibilidade e força aos programas de literatura comparada. ${ }^{38}$ Houve também uma multiplicação nos programas dedicados ao estudo das diferentes regiões geográficas, a maioria dos quais preocupada com teorias de nacionalidade e política da identidade. Os estudos da mulher e também os de cinema se tornaram elementos importantes no currículo universitário, e a pesquisa da literatura passou a ser relativamente descentralizada. Teve então início o questionamento sobre os cânones, e o conceito de literatura nacional foi

37 MAZARRA, Richard A. Graciliano Ramos. op. cit.

38 Ver, por exemplo: LEE, Cremilda Toledo. John Steinbeck, Graciliano Ramos and Jorge Amado: A comparative study. Tese (Doutorado em Literatura Comparada). Texas Tech University, 1981. 
associado a certo imperialismo cultural. Nos anos 1990, com a emergência dos estudos culturais, todos os paradigmas culturais da década anterior e todas as divisões departamentais pareciam a ponto de dar lugar a um interesse geral pela sociologia da cultura, concebida em sentido mais amplo e antropológico.

Mas essas explorações constituíam apenas tendências. Os departamentos acadèmicos mais antigos conservaram-se mais ou menos intactos, e as formas tradicionais e a crítica ou história literária não foram abandonadas. Certas tendências surtiram mais efeito do que outras. No último quartel do século $\mathrm{XX}$, programas de estudos começaram a olhar para trás, para os anos da "boa vizinhança", como inspiração para uma pesquisa renovada, baseada nas relações EUA-América Latina, e o estudo de escritores brasileiros e hispano-americanos passou a enfatizar com maior frequência a análise comparativa com importantes escritores norte-americanos. No caso de Graciliano, estes incluíam Steinbeck, Dos Passos ${ }^{39}$ e, talvez o mais significativo, Faulkner. Em termos gerais, a ênfase teórica nos sistemas de linguagem e a crítica da representação realista convencional abriram caminho a uma reabilitação do modernismo literário pela nova esquerda.

O livro de Graciliano que recebeu maior atenção nesse período foi Vidas secas. Romance brilhante e relativamente breve, era útil para qualquer professor interessado em apresentar o autor alagoano num curso introdutório ou no contexto da literatura comparada ${ }^{40}$. Na tradução de sua importante tese de doutoramento (1986), Hermenêutica \& literatura: Um estudo de As I lay dying, de William Faulkner, e Vidas secas, de Graciliano Ramos (2003) ${ }^{41}$, Nelson Cerqueira analisa o problema do destino da família de retirantes e investe contra críticos, como Vincent, que escreveram sobre sua "estrutura fechada" e conclusão pessimista. Ele se mostra de acordo com os críticos Roberto Ballalai e José Alves, que defendem que Vidas secas contém, no final, uma perspectiva que sugere

39 Cf. VIEIRA, David J. Wastelands and Backlands: John Dos Passos' Manhattan Transfer and Graciliano Ramos' Angústia. Hispania 67, 3, p. 377-82, set. 1984.

40 Cf. GOLDIN, David A. O homem cortês: The role of Seu Tomás da Bolandeira in Vidas secas. Luso-Brazilian Review 20, 2, p. 213-222, inverno 1983; OLIVEIRA, Celso de. Understanding Graciliano Ramos. Columbia: University of South Carolina Press, 1988; HARMON, Ronald M. Angústia e Zero. Hispania 73, 1, p. 66-71, mar. 1990.

41 CERQUEIRA, Nelson. Hermeneutics and Literature: A study of William Faulkner's As I lay dying and Graciliano Ramos' Vidas secas. Tese (Doutorado em Literatura Comparada), Indiana University, 1986; Hermenêutica \& literatura: Um estudo de As I lay dying, de William Faulkner, e Vidas secas de Graciliano Ramos. Trad. Yvenio Azevedo. Bahia: Editora Cara, 2003. 
a esperança. Para Cerqueira, o aspecto fundamental é o contraste entre "Mudança" e "Fuga", o primeiro e o último capítulos do romance. Ele chama a atenção para as diferenças etimológicas dos títulos, considerando que "mudança" enfatiza um movimento aleatório de um lugar para outro, enquanto "fuga" denota a evasão de um perigo. Salienta, ainda, que a família não tem nenhum objetivo em "Mudança", enquanto em "Fuga" a família está se movendo na direção do Sul ou da cidade, embora os retirantes se mostrem incapazes de articular seu exato destino ${ }^{42}$. Cerqueira repara também que, diferentemente do primeiro capítulo, no qual Fabiano e Sinha Vitória quase não falam um com o outro, o último os mostra falando sobre a educação dos filhos e a possibilidade de uma vida melhor.

O principal assunto tratado em Hermenêutica \& literatura, que consiste no primeiro importante estudo comparativo entre Graciliano e Faulkner, é a semelhança de seus temas e estratégias formais. Cerqueira propõe que ambos os escritores criam uma "dialética de substância e processo" ao contrapor sistematicamente as palavras ou pensamentos das personagens às suas ações. O estudioso também observa corretamente que a maioria dos ensaios sobre Vidas secas nos EUA tem a ver com sua representação realista da cultura nordestina e sua crítica social, enquanto os estudos de As I lay dying focalizam invariavelmente o uso que Faulkner fez de mito, simbolismo religioso e temas existenciais. Pode-se acrescentar que, com poucas exceções, os críticos nos EUA seguiram uma bem-estabelecida tradição de considerar Graciliano não como um modernista, mas sim como um representante do regionalismo, do "romance social" e da "geração de 1930"

Nesta época alguns estudos de Vidas secas se dedicaram a pesquisar suas conexões temáticas e estilísticas com Os sertões $^{44}$. Num artigo intitulado "Euclides disseminado: Vidas secas de Graciliano Ramos" (1989) ${ }^{45}$, Leopoldo Bernucci argumenta que, em decorrência da penúria metatextual, ou falta de comentário do escritor sobre seus romances, os críticos têm especulado sobre a influência de outros

42 Idem, ibidem, p. 87. Cf. também: CERQUEIRA, Nelson. Vidas secas: A deconstructable narrative?. Chiricú 3, 1, p. 57-81, 1982.

43 Outros exemplos dessa tendência crítica são os estudos "Vidas secas, de Graciliano Ramos (1973)", de Frederick Williams, e "Symbolism in Graciliano Ramos' Angústia" (1978), de Ronald Harmon.

44. CUNHA, Euclides da. Os sertões. 15 ed. Rio de Janeiro: Francisco Alves, P. de Azevedo e Cia., 1940.

45 BERNUCCI, Leopoldo. Euclides disseminado: Vidas secas de Graciliano Ramos. Luso-Brazilian Review 26, 1, p.1-14, verão 1989. 
autores. Bernucci cita Clara Ramos ${ }^{46}$, que menciona o fato de Graciliano ter apreciado Zola e Eça de Queirós. Com base nisso, o crítico argumenta que, apesar de sua linguagem e espírito modernista, Graciliano era, a seu modo, um "neonaturalista" e que Vidas secas tem maior afinidade com Os sertões do que com os romances "regionalistas" dos anos 1930. Bernucci também nos lembra de que o discurso indireto livre foi bastante usado nos romances naturalistas do século XIX. A diferença que deve ser observada, porém, é que Graciliano retrata com sofisticação os pensamentos de personagens que quase não dispõem de talento verbal - um detalhe estilístico que Bernucci identifica como uma das características mais atraentes e desafiadoras do livro.

Bernucci não é o primeiro crítico a ver ressonâncias de Os sertões em Vidas secas, mas, em seu entusiasmo de mostrar essa ligação, procura dar prova de semelhanças exatas entre os dois livros. Por exemplo, cita os trechos seguintes para ilustrar como "as relações fiéis com o patrão" são representadas:

(Vidas secas) "Fabiano recebia na partilha a quarta parte dos bezerros e a terça dos cabritos. Mas como não tinha roça e apenas se limitava a semear na vazante uns punhados de feijão e milho, comia da feira, desfazia-se dos animais, não chegava a ferrar um bezerro ou assinar a orellha de um cabrito" ${ }^{\$ 7}$.

(Os sertões) "Se é uma vaca e dá cria, ele a ferra com o mesmo sinal desconhecido, que reproduz com perfeição admirável; e assim pratica com toda a descendência daquela. De quatro em quatro bezerros, porém, separa um para si. É a sua paga" ${ }^{\text {" }}$.

Embora esses excertos revelem semelhanças, deve-se notar que há também diferenças importantes entre eles. Euclides da Cunha dá ênfase ao talento do vaqueiro em marcar os animais, habilidade que passa de uma geração a outra. A palavra "porém" na última oração introduz algo positivo, no sentido de que o talento do vaqueiro permite-lhe separar um animal de cada quatro como pagamento pelo seu trabalho. No trecho de Vidas secas, a palavra "Mas", cuja função gramatical é semelhante a "porém", indica falta de direito de propriedade da terra, fato que impede

46 RAMOS, Clara. Mestre Graciliano: Confirmação humana de uma obra. Rio de Janeiro: Civilização Brasileira, 1979.

47 RAMOS, Graciliano. Vidas secas. Rio de Janeiro: Record, 1980. p. $9^{2}$.

48 CUNHA, Euclides. Os sertões. Edição crítica. São Paulo: Ática, 1985. p. 186. 
Fabiano de marcar animais para si mesmo. Esta falta é consistente com outras no romance: falta de dinheiro que Fabiano perde no jogo; falta de honra quando ele é chicoteado e encarcerado; falta de alojamento e cavalo quando a seca volta outra vez.

\section{Graciliano sobre Graciliano}

Desde fins da década de 1980, críticos nos EUA têm-se engajado em debates teóricos sobre a natureza do sujeito-falante na literatura de testemunho e na autobiografia, ou life writing em geral. Isso tem impactado também os estudos sobre Graciliano, com um acréscimo no número de publicações acerca de Infância e Memórias do cárcere, livros raramente abordados nas décadas anteriores. $O$ estudo da obra autobiográfica do autor alagoano começou com o ensaio "Graciliano Ramos' memoirs", de Celso de Oliveira ${ }^{49}$. Embora não considere aspectos teóricos importantes, levantados por críticos como John Paul Eakin ou Eliane Zagury, os quais questionam a relação entre autobiografia e ficção, Oliveira faz várias observações interessantes. Seguindo ideias presentes no volume de Assis Brasil, Graciliano Ramos (1969) ${ }^{50}$, Oliveira chama a atenção para a opção do escritor de estruturar Infância à moda de conto ou formato episódico, como em Vidas secas. Trata também da representação engenhosa de percepções sensoriais em Infância, um texto que combina imagens auditivas, visuais e táteis numa sinestesia prosaica. Talvez o ponto mais importante levantado por Oliveira tenha a ver com o tema da memória. Reconhecendo a influência de $D u$ côté de chez Swann, de Proust, Oliveira se pergunta se Infância (e a autobiografia em geral) é realmente sobre o objeto de uma lembrança (uma pessoa ou experiência), ou, antes, sobre a cópia de um objeto que deriva do discurso ${ }^{51}$. Destaca o reaparecimento de certas imagens-chave, como a cama de couro, associada com Seu Tomás em Vidas secas, e mais tarde com os avós em Infância, e sugere que as fronteiras entre ficção e memória autobiográfica talvez não sejam tão claras como parecem ser. No final, Oliveira considera que Infância é uma obra híbrida (como toda narrativa, talvez), na qual o "eu" autobiográfico de Graciliano reflete sobre um povo e um mundo prefigurados em seus romances.

49 OLIVEIRA, Celso de. Graciliano Ramos' memoirs. Arizona Quarterly 42, 1, p. 17-3o, primavera 1986.

5o BRASIL, Assis. Graciliano Ramos: Ensaio. Rio de Janeiro: Organização Simões, 1969 .

51 OLIVEIRA, Celso de. op. cit. p. 27. 
O estudo de narrativas autobiográficas que enfocam opressão social ou política tem suscitado bom número de ensaios sobre as diferentes formas da literatura de testemunho, sobretudo as memórias de cárcere. No artigo "The odyssey of a humanist", publicado no Journal of Evolutionary Psychology (1987) ${ }^{52}$, Richard Mazzara mostra-se menos preocupado com a política de Memórias do cárcere do que com os assuntos morais e éticos que decorrem de um confinamento imposto. Tais assuntos emergem parcialmente das interações entre Graciliano e os outros prisioneiros, com diferentes posições políticas, profissionais ou sociais. (Embora não o diga especificamente, deve-se notar que o ponto de vista de Graciliano em Memórias é panóptico; isto é, ele vê centenas de prisioneiros-camaradas, relata seus nomes e histórias e, no processo, torna essas histórias individuais uma parte de sua própria narrativa). Mazzara observa que Graciliano mantém sua humanidade apesar do sistema inumano da prisão. Mas o sistema em Memórias do cárcere apresenta várias faces inesperadas: mesmo Alfeu, o guarda brutal na colônia penal, aceita, embora com certo ressentimento, a recusa de Graciliano ao convite para escrever um texto de apresentação para celebrar a chegada do diretor da prisão. A inabilidade de prever a reação e a psicologia humanas é central nas memórias de Graciliano. Como ele demonstra em seus romances, mesmo as pessoas mais humildes e inarticuladas têm pensamentos complexos e, às vezes, contraditórios. Mazzara defende que Graciliano sobrevive na prisão graças ao vínculo especial que mantém com os outros prisioneiros, apesar das barreiras convencionais de política, raça, religião ou classe social. Esse vínculo talvez explique por que os leitores se identificam, em certo nível, com sua luta e com a luta ficcional de uma família remota de retirantes, e mesmo com os sonhos de uma cachorra.

No ensaio "Memórias do cárcere: Between history and imagination" (1999), Joanna Courteau trata do problema do sujeito em autobiografia. "O autor que escreve um roteiro memorialista", observa, "tem que realizar um duplo ato em que ele é, ao mesmo tempo, um e outro, o sujeito e o objeto da narração, simultaneamente o narrado e o narrador, o 'eu' no papel (Barthes) e o 'eu' histórico" ${ }^{55}$. Ela baseia seu argumento no conceito de Lacan do "sujeito significador" e suas características psicanalíticas: aphanisis, ou a tradução de uma experiência histórica em linguagem (no caso de Graciliano, prisão>memórias>narrativa); autonomasis, ou a

52 MAZARRA, Richard A. The odyssey of a humanist: Graciliano Ramos' Memórias do cárcere. Journal of Evolutionary Psychology 8, 1-2, p. 128-135, 1987.

53 COURTEAU, Joanna. Memórias do cárcere: Between history and imagination. Hispania 83,1 , p. 49-55, mar. 1999. p. 49 . 
substituição metonímica/metafórica de um nome (o nome de Graciliano é substituído por 3535, seu número como prisioneiro); e o reflexo no espelho, ou o meio pelo qual o imaginário reflete a história (o discurso narrativo expõe o horror da prisão, mas a representação simbólica protege o narrador da experiência direta do evento). Courteau também considera que o sujeito de Graciliano é um ser ético cujo desejo de simbolizar a história é governado por preocupações morais. Embora essa asserção (ou aphanisis) seja apenas vagamente debatida, ela induz a ensaísta a concluir que as memórias de Graciliano representam a "agência efetiva do sujeito humano" ${ }^{54}$.

A relação entre ética e autobiografia é mais desenvolvida em "The ethical self in Graciliano Ramos' Infância" (2005), de Sabrina Karpa-Wilson ${ }^{55}$. O argumento desse artigo é uma variação do que foi desenvolvido por Eliane Zagury em A escrita do eu $(1982)^{56}$, segundo o qual Infáncia é um texto construído intelectualmente e foi escrito com o propósito de denunciar o sistema educacional do Nordeste. Em geral, Karpa-Wilson concorda com a ideia de Zagury, mas vê a denúncia apenas como parte de um projeto maior de Graciliano, o de "criar uma história coerente do desenvolvimento individual e ético" ${ }^{57}$. Karpa-Wilson baseia seu argumento no que ela entende como um alto grau de seleção e interpretação das experiências lembradas, que criam um "desenho" moral preconcebido ${ }^{58}$. Esse desenho é mediado pelo "eu" do narrador adulto, que, ao contrário do "eu" do protagonista-menino, questiona as noções tradicionais de identidade, daí resultando certo entendimento das experiências do menino enquanto lições morais. Um de seus exemplos é o capítulo intitulado "Um cinturão", que descreve uma surra que o pai de Graciliano lhe deu por um ato que não fez. O capítulo começa e termina com a afirmação de que esse episódio consistiu em sua primeira experiência com a "justiça". Karpa-Wilson mostra como uma lembrança construída por meios literários pode tornar-se a fonte não só de uma crítica ao passado, mas também de maior reflexão sobre a lição aprendida em relação a experiências posteriores.

Em síntese, o estudo de Karpa-Wilson aborda a diferença entre escritores como José Lins do Rego e Cyro dos Anjos, cuja obra memoria-

54. Idem, ibidem, p. 50-51

55 KARPA-WILSON, Sabrina. The ethical self in Graciliano Ramos' Infancia. Luso-Brazilian Review 4,2, 1, p. 154-178, 2005.

56 ZAGURY, Eliane. A escrita do eu. Rio de Janeiro: Civilização Brasileira, 1982.

57 KARPA-WILSON, Sabrina. op. cit. p. 155.

$5^{8}$ Idem, ibidem, p. 156.

SI

revista ieb $\quad n 54 \quad 2012$ set./mar. p. 31-52 
lística revela uma nostalgia daquilo que Roberto Reis ${ }^{59}$ chama de "cena senhorial" ou passado patriarcal, e a de Graciliano, cujas memórias expõem o chauvinismo e a brutalidade do patriarcado. Segundo KarpaWilson, Infância é obra complexa demais em sua recriação da juventude e da viagem rumo à iluminação pessoal para ser lida como nostalgia do passado ${ }^{60}$. A estudiosa demonstra, efetivamente, que o retrato do artista quando jovem em Infância é muito mais sutil e psicologicamente complexo do que a maioria das narrativas autobiográficas; e que sua estrutura episódica, na tradição de muita literatura romântica e modernista, oferece epifanias de maravilhas e dificuldades da infância no Brasil rural.

\section{Graciliano e o cinema}

A obra de Graciliano continua a ser estudada em cursos de literatura e de cultura, e a adaptação de Vidas secas por Nelson Pereira dos Santos, recentemente restaurada, serve para examinar mais detalhadamente a obra clássica do alagoano ${ }^{61}$. Não há dúvida de que a incorporação de filmes como Vidas secas, São Bernardo e Memórias do cárcere em cursos de cinema e de literatura e adaptação está chamando a atenção de uma nova geração de estudantes universitários nos EUA para os livros de Graciliano e para uma região que ainda transpassa e continua associada ao célebre escritor.

59 REIS, Roberto. A permanência do círculo: Hierarquia no romance brasileiro. Niterói: EdUFF, 1987 .

60 KARPA-WILSON, Sabrina. op. cit. p. 173.

61 Ver, por exemplo, os estudos críticos de Randal Johnson e de Darlene J. Sadlier sobre as adaptações de Vidas secas e Memórias do cárcere: JOHNSON, Randal. Vidas secas and the politics of filmic adaptation. Ideologies \& Literatures 3, 15, p. 3-18, jan.mar. 1981; SADLIER, Darlene J. Nelson Pereira dos Santos. Chicago: University of Illinois Press, 2003.

52

revista ieb $\quad$ n54 2012 set./mar. $p .31-52$ 